\title{
Well logging interpretation methodology for carbonate formation fracture system properties determination
}

\author{
Marek Stadtmüller ${ }^{1}$ (D)
}

Received: 8 May 2019 / Revised: 26 August 2019 / Accepted: 28 August 2019 / Published online: 9 September 2019

(c) The Author(s) 2019

\begin{abstract}
The article presents the methodology for the qualitative determination of fracture zones in the profiles of carbonate formations, based on the complex fracture analysis (CFA) method. Three additive fracture ranges were distinguished, characterized by successively increasing aperture and fracture length values, operatively named micro, meso and macro. Furthermore, the quantitative characterization of fractures with different apertures was done. The methodology of laboratory data integration, fracture porosity and fracture permeability measurements performed on thin section and polished section was described as part of the quantitative well logging data interpretation procedure which uses the FPI (fracture porosity index) parameter. The research was performed in the Lower Carboniferous limestone formation that builds the Paleozoic basement of the Carpathian orogeny. An original software dedicated to the analysis of the wellbore images, obtained with the XRMI Halliburton scanner, was used to identify the presence of macro-fractures, determine their aperture and estimate fractures porosity and permeability in the profile of the analyzed rock formation. As a result of the work, postulates regarding the methodology for collecting research material were formulated, in particular: the scope of different laboratory core samples measurements and well log types. The principles of the optimal methodology for identifying fractured zones and quantitative evaluation of petrophysical parameters of recognized fracture systems were defined.
\end{abstract}

Keywords Well logging · Carbonate formations · Fracture system · Petrophysical parameters · Quantitative interpretation · Fracture porosity $\cdot$ Fracture permeability

\section{Introduction}

Carbonate formations are generally characterized by a very complex porosity system containing primary porosity (matrix porosity) and secondary porosity system which consists of discontinuities with various apertures from micro-scale, below $0.1 \mathrm{~mm}$ through meso, above $0.1 \mathrm{~mm}$ to macro, which can easily be visible without microscope. The secondary porosity also includes all forms of caverns, vugs and voids in rock of various origins. Such rocks are called "double porosity rocks" (Archie 1952; Lucia 1999). A precise estimation of the type and size of secondary porosity in carbonate formations is crucial for the prediction of rock permeability and for the determination of geological and recoverable hydrocarbon resources. The problem with the

Marek Stadtmúller

stadtmuller@inig.pl

1 Oil and Gas Institute-National Research Institute, Lubicz 25 A, 31-503 Kraków, Poland estimation of secondary porosity based on borehole measurements has been the subject of numerous research works dealing with the impact of cavities and caverns on well log data and developing interpretive techniques (Aguilera 1976; Brie et al. 1985; Dutta et al. 1991; Kazatchenko and Mousatov 2002; Kazatchenko et al. 2003). Currently, work is underway to quantify the pore space parameters of carbonate formations based on nano-CT (computed X-ray tomography) measurements (Puskarczyk et al. 2018). An interesting approach seems to be the generating porosity spectrum based on ultrasonic imaging log (Zhang et al. 2018). The general approach to qualitative fracture analysis is the methodology of complex fractures analysis (CFA) proposed by (Sowiżdżal and Stadtmúller 2010). This approach assumes the use of well log data as a specific indicator of the presence of fractures that are interpreted simultaneously and allow to divide the analyzed formation into: fracture zones, partially fractured zones and zones without the presence of discontinuities. The secondary porosity prediction must be based on laboratory tests conducted on the representative 
number of core samples for a given rock formation. In practice, this may cause difficulties because the most important open macro-fractures which have the major impact on media flow in the formation usually are damaged during the process of coring. The measurements of the so-called acoustic or electrical imagers allow the imaging of wellbore walls and recognition of the geometry of individual fractures (direction and dip angle). In addition, after an appropriate processing of the data it is possible to estimate the aperture of the fracture presented on the image of well wall (Luthi and Souhaite 1990). This article presents the procedures for estimating secondary porosity systematization based on laboratory measurements and well log data.

\section{Geological and petrophysical background}

The carbonated formations of Paleozoic strata (Carboniferous and Devonian) in the considered area are localized in the south-eastern part of the tectonic structure known as the Upper Silesian Block, and they are lying around $4500 \mathrm{~m}$ below sea level. They are composed of organogenic limestone deposited in the carbonated platform environment, locally with slight admixture of dolomitic and clay material forming marly layer having the meaning of correlation level (Narkiewicz 2001). From the Dunham classification point of view, the limestone is of a packstone type (Dunham 1962), characterized generally by little total porosity, not exceeding $5 \%$ with an average value below $0.5 \%$. The laboratory data of the permeability measurements conducted on well core samples indicate the complete lack of permeability of the rock matrix. Description of the cores and cuttings indicates the importance of the fracture systems presence that is fundamentally significant in the reservoir fluids transport. The relatively low inflow of gasified brines during the perforations allows for the presumption about the perspective nature of the carbonated formations of Lower Carboniferous as reservoir rocks for oil or gas (Urbaniec 1998).

\section{CFA methodology}

The CFA methodology is based on the analysis of anomalies of particular logs on the account of possible fracture presence. It is a qualitative method, and it has a strictly local character as every time it requires estimating the base anomaly level, or in other words the anomaly that does not include the present fractures influence. The shape of the studied anomaly as well as its sharpness and the rate of its changes are also helpful while using the method.

For particular logs, it is possible to distinguish their qualities that indicate the presence of the fractures.
- Caliper Log-increasing the diameter of sharp and narrow shape;

- Resistivity Log-lowering the general resistivity, rapid changes in the levels of readings, especially on the short tool;

- Neutron Log-increase in the readings;

Density Log_decrease measured density, especially in case of sharp and narrow anomalies;

- Acoustic Log-general increase in the readings, no changes in the readings levels only in case of the presence of vertical fractures. Consequently, the measured neutron and density porosity exceeds the acoustic porosity;

- Spectral Gamma Log-significant increase in the Uranium rock content;

- DipMeter Log —no rotation of the device and resistance anomalies registered on the opposite pad on the result of the DIPROT processing, concerns the presence of vertical or semi-vertical fractures;

- Imaging Log — direct observation of macro-fractures on the image of well walls;

It is accepted that fulfilling at least five of the above conditions classifies a particular profile interval of a well as fractured. Three of the conditions indicate the partially fractured, and below that the interval is considered not fractured.

\section{Laboratory data}

The research was conducted on a collection of 89 samples of carbonate rocks from nine boreholes drilling carbonate formation of the Paleozoic basement of the Carpathian orogen. The samples were collected by the Oil and Gas InstituteNational Research Institute over the last 30 years (Leśniak and Darłak 1995). Data included determination results of fracture porosity and fracture permeability for two ranges of fracture apertures. Porosity (PORmfr [\%]) and permeability (PERMmfr $[\mathrm{mD}]$ ) in the micro-range were determined by inspection of thin sections, for fractures of aperture below $0.1 \mathrm{~mm}$. Porosity (PORpfr [\%]) and permeability (PERMpfr $[\mathrm{mD}])$ in the meso-range, for fractures with aperture above $0.1 \mathrm{~mm}$, were determined based on the analysis of polished sections. Moreover, pycnometry and porosimetry studies were also carried out to estimate the total porosity (PHIt [\%]) and effective porosity (PHIef [\%]) for each sample. Afterward, a simple sum was made to obtain the estimation of the total fracture porosity (PORfr [\%] and total fracture permeability (PERMfr $[\mathrm{mD}]$ ) in micro- and meso-ranges. The methodology of estimating the above parameters was described by Paduszyński (1965), named by the author the "random traverse method." The method uses microscope (in case of the thin sections) or using a projector upgraded 
with a millimeter grade (in case of polished sections) to planimetry them. In both cases, the measurements taken include estimating the density and aperture of the fractures that can be seen in the ocular of the microscope. The data obtained are used as input for mathematical models of fracture porosity and permeability, so the final values are calculated. The resulting parameters should be treated as expected values of random variables, because these measurements are performed repeatedly on many preparations to obtain a representative random sample. The method has a statistical nature. Assumptions are made about the smoothness and lack of tortuosity of micro-fractures, the length much greater than the aperture. Constants dependent on the individual data set selection causes that the obtained results are generally relative trends rather than exact absolute values. This fact has significant consequences in the application of the data in the quantitative interpretation of petrophysical parameters based on well log data. The complete list of the results obtained from the research described above is presented in Tables 1 and 2.

The analyses of the collected data show at first glance the inconsistency illustrated in Fig. 1. Almost all measurements of fracture porosity are greater than the values obtained from the pycnometry total porosity measurement. Only samples 76-86 do not follow this trend, which may indicate the presence of a component such as cavernous porosity, open and connected caverns. A clear local trend of proportionality between PHIt and PORfr can be noticed for the other samples.

\section{Well logging data}

The collected well log data come from wells drilled, in the period, from the early nineties of the twentieth century to the present day. The standard measurement set usually includes: GG [API]—total gamma ray intensity, GRS [API] — gamma ray intensity from spectral gamma ray log built of potassium and thorium windows, URAN [ppm]uranium content, THOR [ppm]-thorium concentration, POTA [\%]—potassium concentration, NPHI [\%]—neutron porosity, DT $[\mu \mathrm{s} / \mathrm{ft}]$ - compressional slowness, RHOB [g/ cc]—bulk density, DRHO[g/cc]—bulk density correction, PEF [barn/electron] - photoelectric absorption index, LLD [ohmm], LLS [ohmm], MSFL [ohmm]—resistivity logs of different radial ranges, WSTT-full-waveform sonic data, SED-dipmeter measurements, CAST, XRMI-acoustic and electric wellbore scanners, respectively. The result of the quantitative interpretation as regards mineral composition and total porosity was also available. SPI (direct porosity index) was calculated directly from the well log data as the difference between neutron and acoustic porosity (Aguilera 1976). This parameter quantifies the part of total porosity which is associated with the presence of secondary porosity. The secondary porosity does not exceed $0.25 \%$, in the most cases described in the literature, so its absolute values are small, while its relative values may exceed 20\% (Crain's Petrophysic Handbook). Figure 2 confirms this fact, showing the histogram of SPI results within carbonate formations of the Lower Carboniferous. Estimated values range from $0-0.0143 \%$.

The input set of laboratory data that contained the Carboniferous and Devonian formation comes from nine wells localized in different parts of the studied region. In addition, there was no well logging in some of them. Consequently, the laboratory data from samples taken from only one stratigraphic unit and one well could be taken into consideration during the analysis. During the selection process, 13 samples were selected (Table 3), within the compacted limestone formation of the Lower Carboniferous formation with very low shale volume and locally with small amount of dolomite admixtures. According to the geological macroscopic description (Urbaniec 1998), the cores are organodetritic limestone, bituminous, massive, with numerous cracks and irregular systems of multi-directional fractures, mostly filled with calcite or dolomite, locally cavernous. Then, the selected core samples were used to carry out the procedure of quantitative interpretation of secondary porosity.

\section{Interpretation methodology}

Based on the laboratory core data, a fundamental methodological assumption has been made about the existence of three independent ranges of apertures in the interpreted formation, and hence, three independent systems of fractures were defined:

- micro-fracture range: aperture- $\mathrm{a}<0.1 \mathrm{~mm}$; (thin sections),

- meso-fracture range: aperture-a $>0.1 \mathrm{~mm}$; (polished sections),

- the macro-fracture whose apertures are so large that it can be identified on the wellbore scanner images or visible on core samples (polished sections, well log data, cores).

The second fundamental assumption is a linear additivity of partial effects caused by particular types of fractures with different apertures to estimate the total amount of fractures present in the formation. This assumption allows estimating the parameters of fractures, fracture porosity and fracture permeability for each specified range separately, and obtain a total effect in the form of a sum or a weighted sum.

The third fundamental assumption is an adoption of the results of the fracture porosity estimation both for thin 


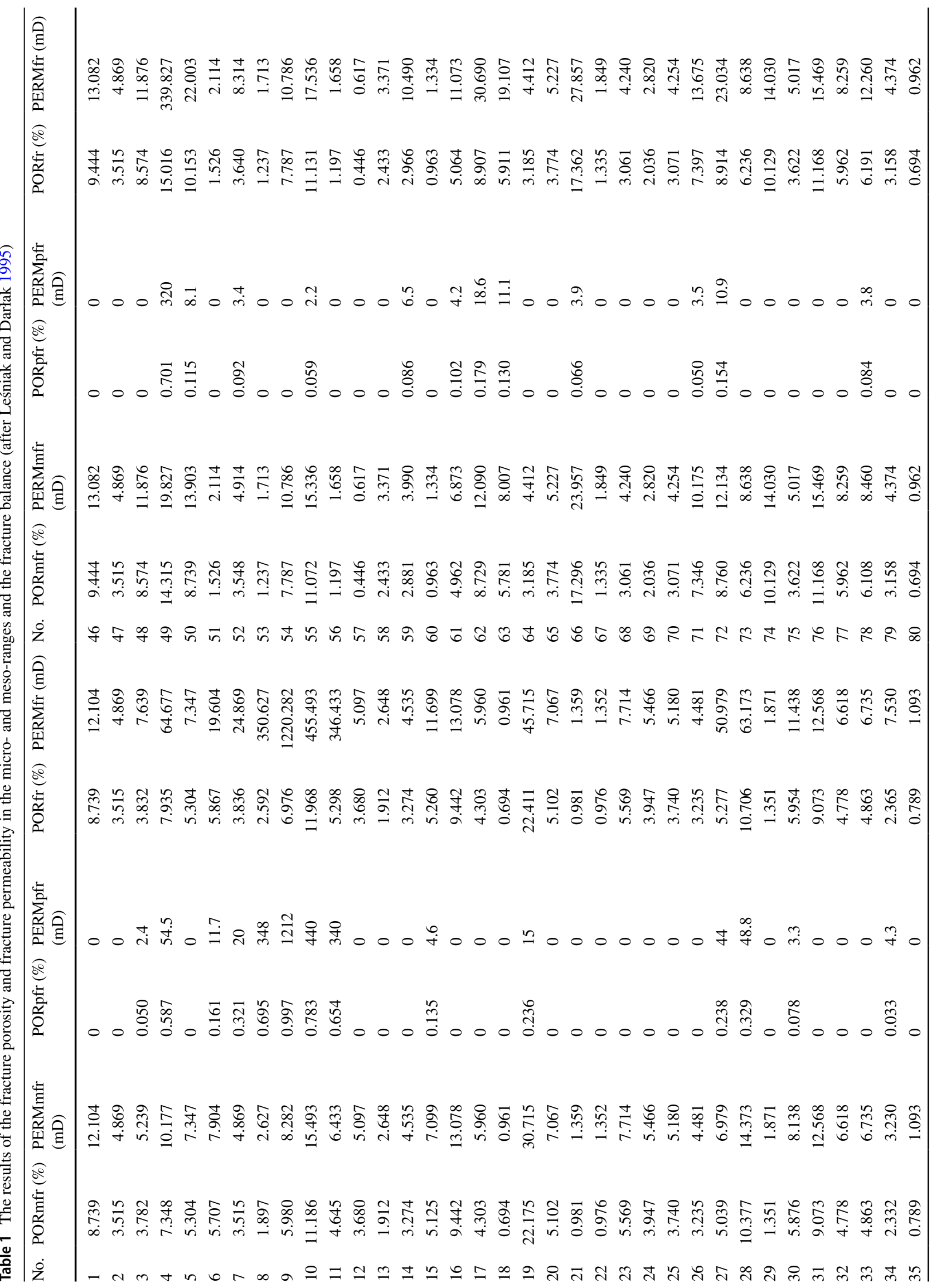




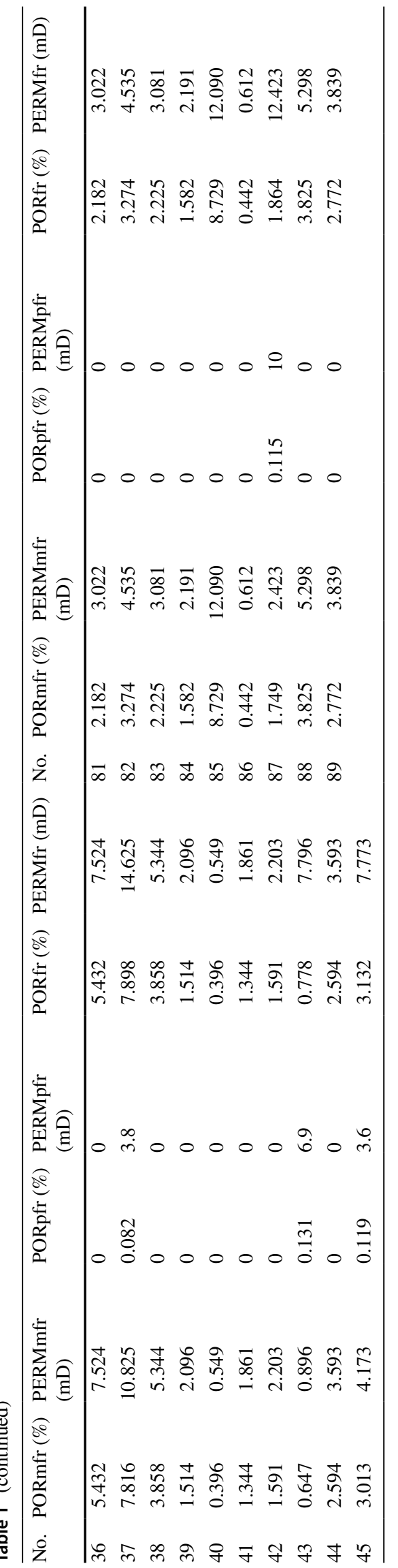

sections and polished sections as relative values and the calculation of the FPI (fracture porosity index) parameter according to Eq. (1).

FPIfr $=\frac{\text { PORfr }}{100} \times$ PHIt [\%]

where PORfr $=$ PORmfr + PORpfr.

Physical meaning of the FPI parameter is the same as discussed earlier for the SPI parameter. It can be calculated separately for the micro (FPImfr) range, the meso (FPIpfr) range and for the sum (FPIfr). Obtained values of FPI parameters for particular fracture apertures are presented in Table 3. The 13th row of Table 3 comes from the 14th row of Tables 1 and 2.

The obtained data were investigated in terms of the existence of possible correlations between individual variables. Few interesting correlations were obtained with relatively high determination coefficient $\left(\mathrm{R}^{2}\right)$, from the range (0.312-0.812). Relationships described by Eqs. 2-4 are also presented in Figs. 3, 4, 5.

- for the micro-range

$$
\text { FPImfr }=0.038 \times \ln (\text { PHIt })+0.061 \quad R^{2}=0.812 \text { (Fig. 3) }
$$

$$
\text { PERMmfr }=5.326 \times \ln (\text { FPImfr })+29.15 \quad R^{2}=0.729 \text { (Fig. } 4 \text { ) }
$$

- for the meso-range

$$
\begin{aligned}
& \text { FPIpfr }=0.093 \times \text { FPImfr }+0.00005 \quad R^{2}=0.803(\text { Fig. } .5) \\
& \text { PERMpfr }=156.3 \times \ln (\text { FPIpfr })+1288 \quad R^{2}=0.310
\end{aligned}
$$

The function between PERMpfr vs. FPIpfr (Eq. 5) was established after rejection of outlying permeability points (marked in bold in Table 3). The reason for this fact is not currently known, perhaps it results from measurement or calculation errors. The determination coefficient for this relation is low (0.31).

Based on the correlations between core measurements [Eqs. (2-5)], calculations of continuous values of FPImfr, FPIpfr, FPIfr parameters along the profile of the analyzed formation were performed. Fracture permeability (PERMfr $[\mathrm{mD}])$ was estimated as a weighted sum of micro- and mesopermeabilities according to Eq. (6).

PERMfr $=($ FPImfr $\times$ PERMmfr $)+($ FPIpfr $\times$ PERMpfr $)$

The results are illustrated in Fig. 6 containing the following tracks, respectively: the results of quantitative interpretation of mineral composition and porosity, input 
Table 2 The results of pycnometry and porosimetry measurements corresponding to the samples from Table 1 (after Leśniak and Darłak 1995)

\begin{tabular}{|c|c|c|c|c|c|c|c|c|}
\hline No. & PHIt (\%) & PHIef (\%) & No & PHIt (\%) & PHIef (\%) & No. & PHIt (\%) & PHIef (\%) \\
\hline 1 & 0.33 & 0.33 & 35 & 0.38 & 0.38 & 69 & 0.00 & 0.00 \\
\hline 2 & 0.48 & 0.48 & 36 & 0.18 & 0.18 & 70 & 7.08 & 6.81 \\
\hline 3 & 0.25 & 0.25 & 37 & 0.00 & 0.00 & 71 & 2.74 & 2.49 \\
\hline 4 & 0.34 & 0.34 & 38 & 0.33 & 0.33 & 72 & 3.99 & 3.66 \\
\hline 5 & 0.39 & 0.39 & 39 & 0.69 & 0.69 & 73 & 1.31 & 1.16 \\
\hline 6 & 0.27 & 0.27 & 40 & 0.30 & 0.30 & 74 & 3.60 & 3.40 \\
\hline 7 & 2.72 & 2.64 & 41 & 0.63 & 0.61 & 75 & 2.07 & 1.99 \\
\hline 8 & 0.26 & 0.25 & 42 & 1.32 & 1.32 & 76 & 1.28 & 1.24 \\
\hline 9 & 0.91 & 0.90 & 43 & 1.74 & 1.74 & 77 & 0.67 & 0.63 \\
\hline 10 & 0.43 & 0.43 & 44 & 1.12 & 1.10 & 78 & 0.43 & 0.43 \\
\hline 11 & 0.40 & 0.40 & 45 & 0.82 & 0.82 & 79 & 1.21 & 1.20 \\
\hline 12 & 0.56 & 0.56 & 46 & 0.47 & 0.47 & 80 & 2.00 & 1.94 \\
\hline 13 & 1.32 & 1.32 & 47 & 0.37 & 0.37 & 81 & 9.55 & 9.01 \\
\hline 14 & 0.46 & 0.46 & 48 & 0.52 & 0.51 & 82 & 3.61 & 3.54 \\
\hline 15 & 0.00 & 0.00 & 49 & 0.84 & 0.82 & 83 & 7.68 & 6.92 \\
\hline 16 & 0.21 & 0.21 & 50 & 2.95 & 2.81 & 84 & 11.77 & 10.80 \\
\hline 17 & 0.54 & 0.53 & 51 & 1.61 & 1.56 & 85 & 3.83 & 3.65 \\
\hline 18 & 0.49 & 0.49 & 52 & 0.42 & 0.41 & 86 & 1.43 & 1.36 \\
\hline 19 & 0.64 & 0.64 & 53 & 0.00 & 0.00 & 87 & 2.82 & 2.74 \\
\hline 20 & 0.79 & 0.79 & 54 & 0.66 & 0.66 & 88 & 1.99 & 1.86 \\
\hline 21 & 0.53 & 0.52 & 55 & 0.00 & 0.00 & 89 & 3.48 & 3.31 \\
\hline 22 & 1.02 & 1.02 & 56 & 0.89 & 0.89 & & & \\
\hline 23 & 1.24 & 1.23 & 57 & 0.47 & 0.47 & & & \\
\hline 24 & 0.00 & 0.00 & 58 & 0.00 & 0.00 & & & \\
\hline 25 & 1.90 & 1.88 & 59 & 0.40 & 0.38 & & & \\
\hline 26 & 2.03 & 2.01 & 60 & 0.48 & 0.48 & & & \\
\hline 27 & 1.12 & 1.11 & 61 & 0.37 & 0.37 & & & \\
\hline 28 & 0.37 & 0.37 & 62 & 0.63 & 0.63 & & & \\
\hline 29 & 0.67 & 0.67 & 63 & 0.45 & 0.44 & & & \\
\hline 30 & 1.23 & 1.23 & 64 & 13.39 & 13.39 & & & \\
\hline 31 & 0.44 & 0.44 & 65 & 0.00 & 0.00 & & & \\
\hline 31 & 0.60 & 0.59 & 66 & 0.37 & 0.37 & & & \\
\hline 33 & 1.18 & 1.18 & 67 & 1.22 & 1.18 & & & \\
\hline 34 & 0.22 & 0.22 & 68 & 0.30 & 0.30 & & & \\
\hline
\end{tabular}
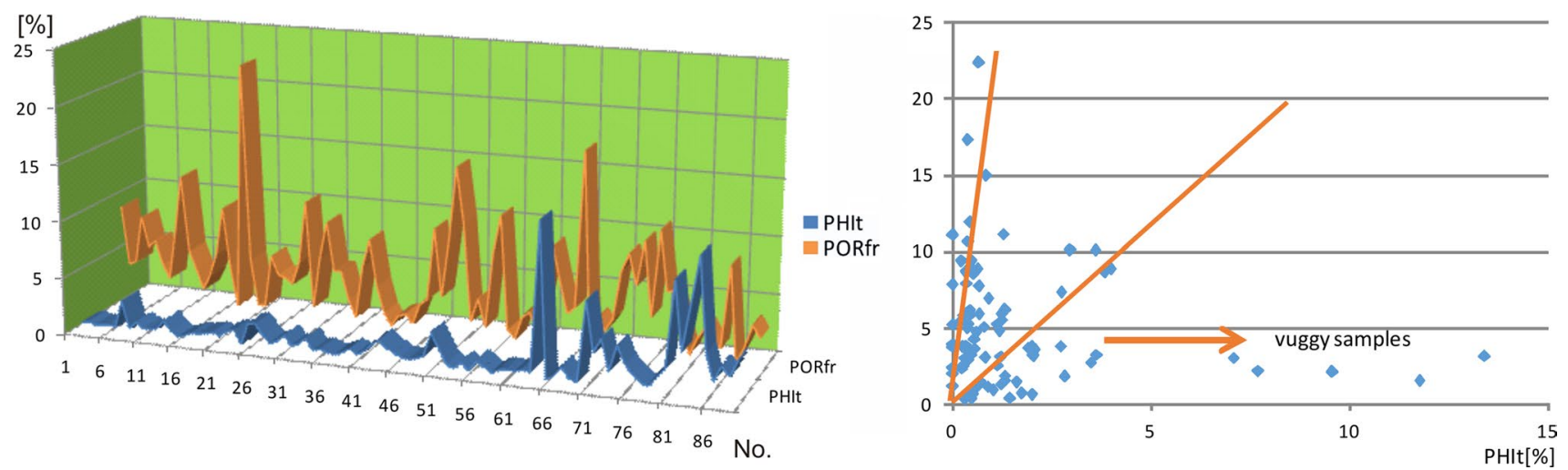

Fig. 1 Plot of PHIt and PORfr laboratory data as a function of the sample number and in cross-plot form 


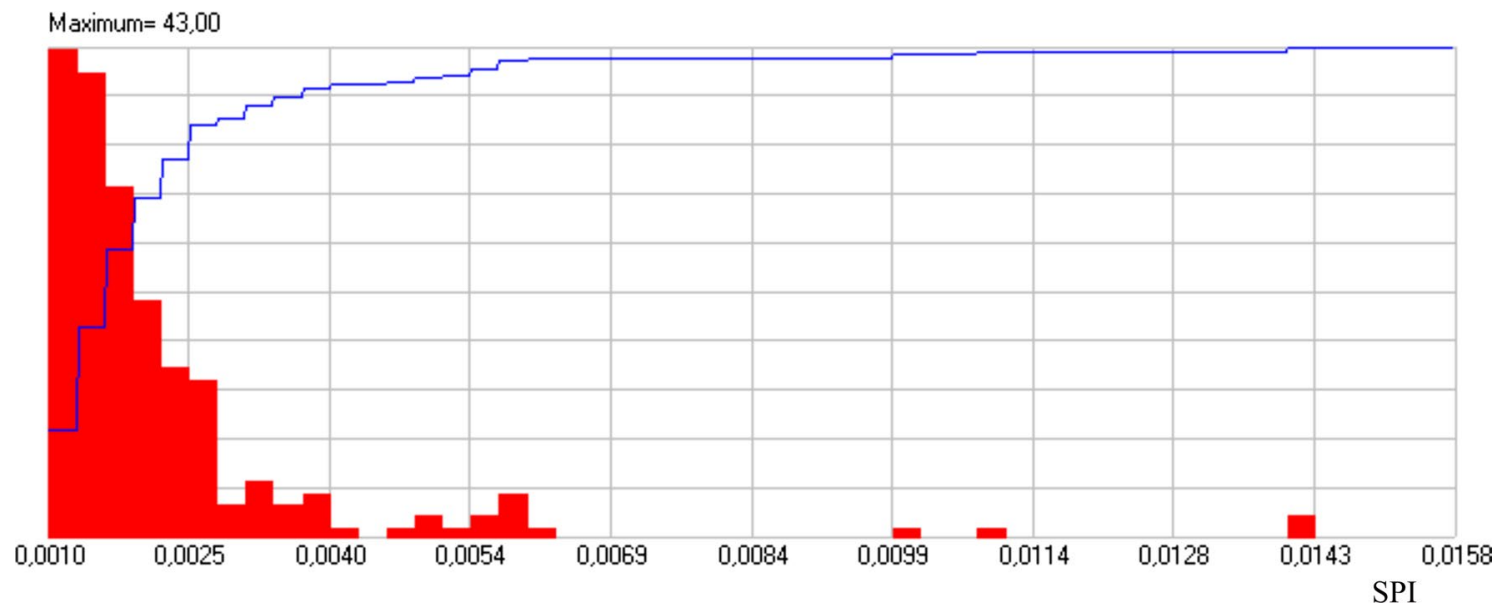

Fig. 2 Histogram of the SPI distribution

Table 3 The list of fracture parameters and calculated FPI values for selected laboratory data of the Lower Carboniferous limestone samples

\begin{tabular}{lllllllllll}
\hline No. & PHIt $(\%)$ & PHIef $(\%)$ & PORmfr $(\%)$ & PORpfr (\%) & PORfr $(\%)$ & FPImfr $(\%)$ & FPIpfr (\%) & FPIfr (\%) & PERMmfr (mD) & PERMpfr (mD) \\
\hline 1 & 0.33 & 0.33 & 8.739 & N/A & 8.739 & 0.0297 & N/A & 0.0297 & 12.104 & N/A \\
2 & 0.48 & 0.48 & 3.515 & N/A & 3.515 & 0.0170 & N/A & 0.0170 & 4.869 & N/A \\
3 & 0.25 & 0.25 & 3.832 & 0.050 & 3.832 & 0.0095 & 0.0001 & 0.0096 & 5.239 & 2.4 \\
4 & 0.34 & 0.34 & 7.935 & 0.587 & 7.935 & 0.0250 & 0.0020 & 0.0270 & 10.177 & 54.5 \\
5 & 0.39 & 0.39 & 5.304 & N/A & 5.304 & 0.0207 & N/A & 0.0207 & 7.347 & N/A \\
6 & 0.27 & 0.27 & 5.867 & 0.161 & 5.867 & 0.0154 & 0.0004 & 0.0158 & 7.904 & 11.7 \\
7 & 2.72 & 2.64 & 3.836 & 0.321 & 3.836 & 0.0956 & 0.0087 & 0.1043 & $\mathbf{4 . 8 6 9}$ & 20 \\
8 & 0.26 & 0.25 & 2.592 & 0.695 & 2.592 & 0.0049 & 0.0018 & 0.0067 & 2.627 & 348 \\
9 & 0.91 & 0.90 & 6.976 & 0.997 & 6.976 & 0.0544 & 0.0091 & 0.0634 & $\mathbf{8 . 2 8 2}$ & 1212 \\
10 & 0.43 & 0.43 & 11.968 & 0.783 & 11.968 & 0.0476 & 0.0033 & 0.0509 & 15.493 & 440 \\
11 & 0.40 & 0.40 & 5.298 & 0.654 & 5.298 & 0.0186 & 0.0026 & 0.0212 & 6.433 & 340 \\
12 & 0.56 & 0.56 & 3.680 & N/A & 3.680 & 0.0206 & N/A & 0.0206 & 5.097 & N/A \\
$13 /(14)$ & 0.46 & 0.46 & 4.535 & N/A & 4.535 & 0.0279 & N/A & 0.0279 & $\mathbf{2 . 6 4 8}$ & N/A \\
\hline
\end{tabular}

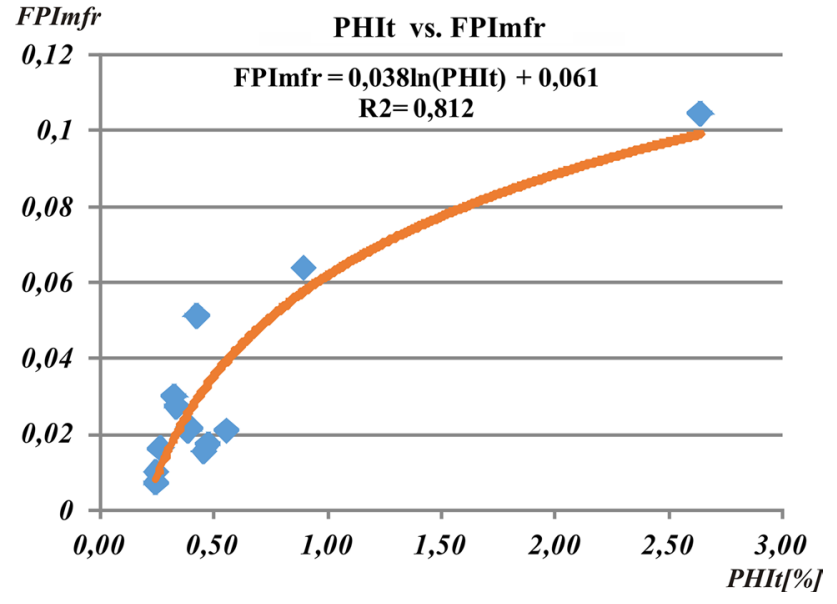

Fig. 3 Correlation between FPImfr and total porosity PHIt, the micro-fracture range

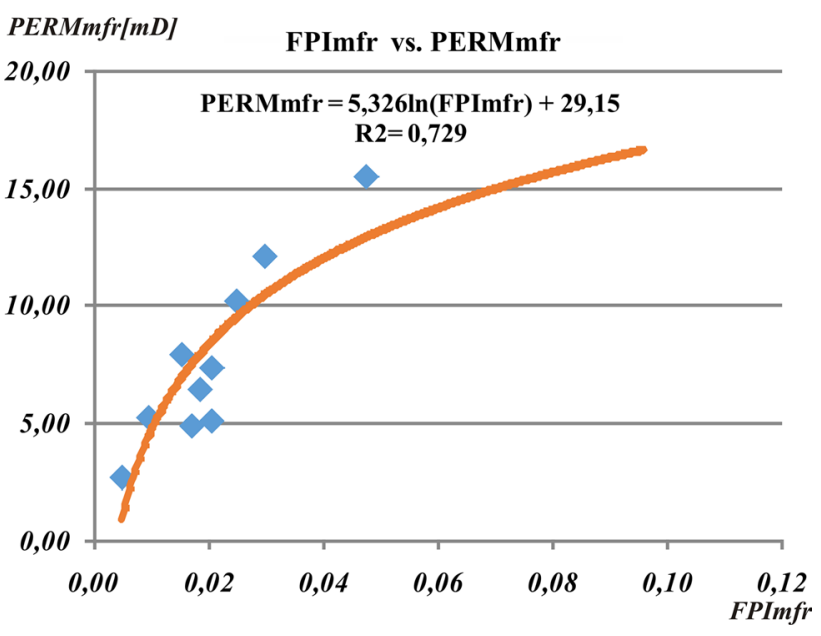

Fig. 4 Correlation between PERM mfr and FPImfr, micro-permeability range 


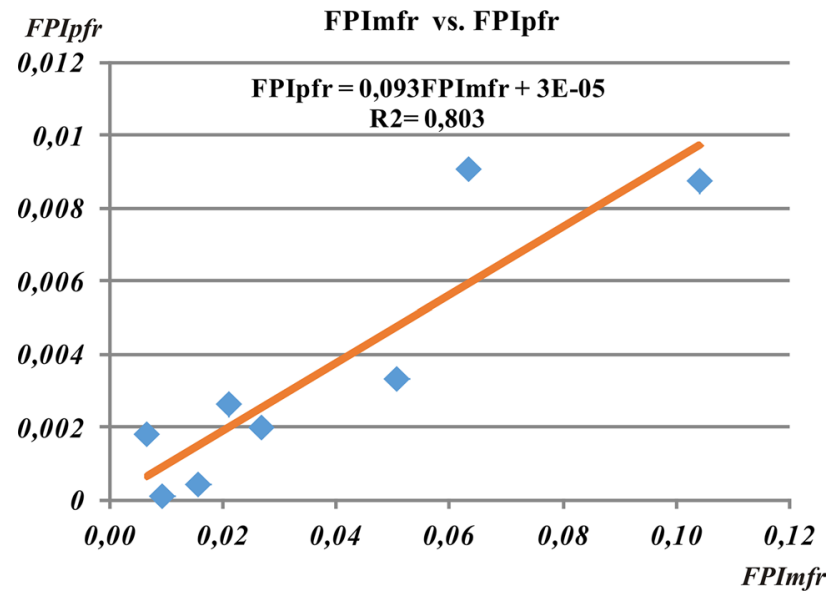

Fig. 5 Correlation between FPfr and FPImfr, meso-range

well logs, porosity analysis together with laboratory data PHIt and raw PORfr, results of fracture analysis in microand meso-ranges, comparison of FPIpfr curve and SPI parameter and in the last column calculated fracture permeability curve PERMfr.

Analysis of the obtained results requires to pay attention to the fact that fractures of the meso-range constitute about one-tenth of the micro-range and, as regards the order of magnitude, it is comparable to the SPI parameter while its contribution to the permeability is many times greater than the others. Zones with increased concentration of fissures correspond with the anomalies recorded on individual well logging curves, especially URAN (uranium content), SPHI (acoustic porosity) and DPHI (density porosity), and in these intervals we observe a significant increase in borehole diameter. Calculated fracture permeability values, PERMfr, covers the range 0.3-3.24 $\mathrm{mD}$ (avg $0.95 \mathrm{mD}$ ). The average value of fracture permeability was compared with the average permeability Ktest $=0.99$ md (Fig. 6 black-dashed line on TRACK 10), estimated from borehole tests carried out in the examined part of the well (Urbaniec 1998). High compliance of these values may lead to the conclusion that in the Lower Carboniferous strata of the considered area, only the micro- and meso-fractures systems correspond to the flow of reservoir media. Total porosity of these fracture systems does not exceed $0.3 \%$. The presented analysis is in some way incomplete, because it does not include the entire secondary porosity in the macro-range. Unfortunately, no electric borehole scanner was available in the analyzed borehole, so to supplement the methodical aspects of the secondary porosity analysis, data from a different borehole which drilled similar carbonate Lower Carboniferous deposits were used.

\section{Macro-fractures evaluation}

The methodology for determining the aperture from electrical imagers of a borehole presented in the paper (Luthi and Souhaite 1990) has been applied and organized into one procedure allowing automatic identification of fracture trace and their parameterization (Stadtmúller and Kowalik 2012). The procedure was organized in the ProGeo software system and consists of several stages.

- Stage I: Removal of gaps between pads to obtain a consistent vector log;

- Stage II: Image filtration using skeletonization algorithms to trace fractures;

- Stage III: On the basis of traces of fractures, calculation of the aperture according to the formula (7)

$w=c \times A \times R m^{b} \times R x 0^{1-b}$

where $c$-constant proportional to the geometric coefficient of the tool $\left[\mu \mathrm{m}^{-1}\right], A$-electrical resistivity of the rock $[\mu \mathrm{A} * \mathrm{~mm}], R m, R x 0$-electrical resistivity of the mud and rocks, respectively, without fractures [Ohmm], $b$-calibration constant.

In Fig. 7, the subsequent analysis steps results, including data processing, filtration and fracture routing, aperture estimation, FPI (fracture porosity index) defined as the ratio of areas occupied by traces of fractures to total surface of wellbore wall calculations, are presented. The next steps of the analysis should include analogous actions as previously described for the micro- and meso-ranges, which should not cause any difficulties if we have all data obtained within the same formation.

\section{Discussion of the results}

The presented results illustrated an important stage in the development of interpretation procedures concerning secondary porosity analysis for rock formation with double porosity. Systematization of the procedure for the use of laboratory data closely integrated by analyzing SPI and FPI parameters with a standard approach to the interpretation of well logs will allow for more detailed 


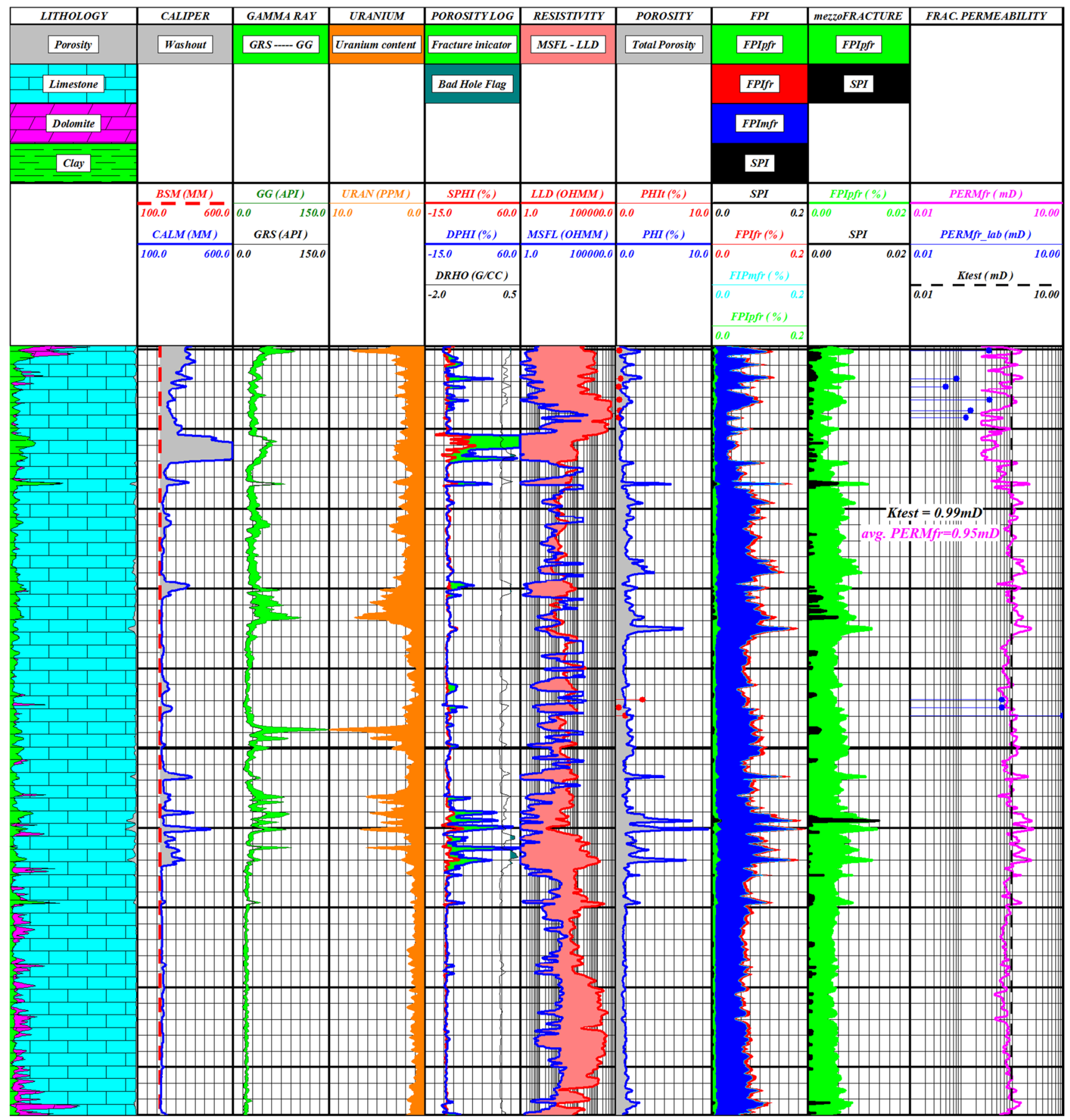

Fig. 6 Interpretation results of the secondary porosity analysis of the carbonate Lower Carboniferous formation

design of specific laboratory measurements in the future, both in terms of their diversity and density of core sampling in given horizon. A graphical representation of the variability of the obtained macro-fracture aperture data is presented in the form of a histogram in Fig. 8a, FPIfr estimation in Fig. 8b, laboratory data on fracture porosity
PORfr in Fig. 8c. It is seen that laboratory data cover only the micro- and meso-ranges, while in the FPI values the macro-range is clearly visible. The shape of the aperture distribution is a surprise. Although the dominant element is in the range of macro-fractures, one can also notice a significant influence of the meso-range and a small impact 


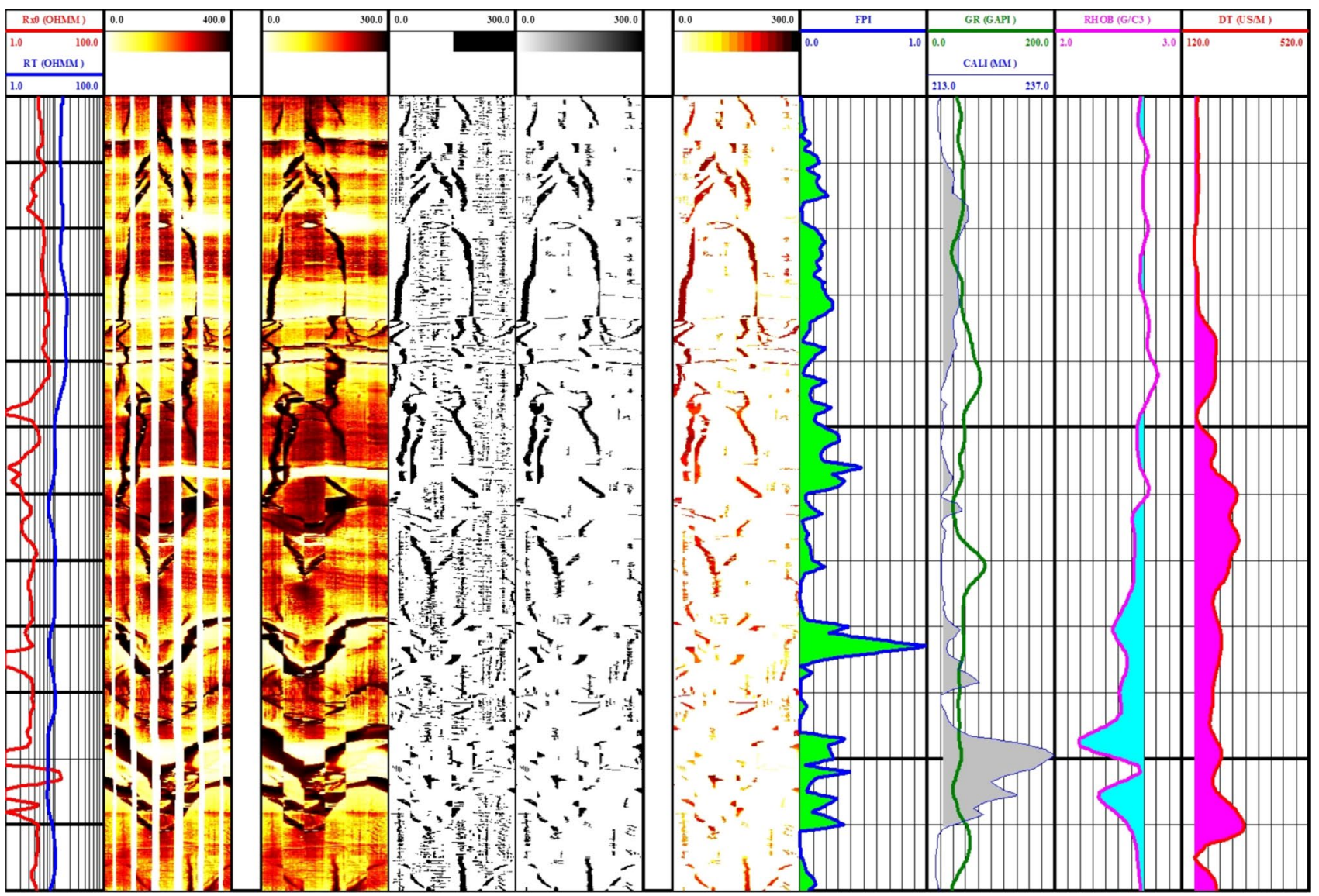

Fig. 7 The example of results of FPI analysis in macro-fractures range, with CFA elements

(a)

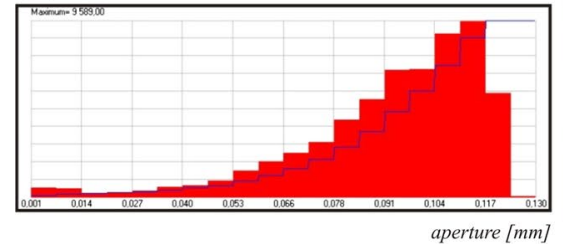

(b)

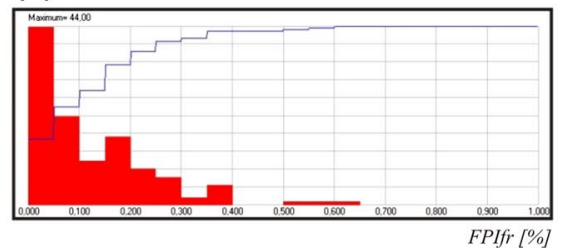

(c)

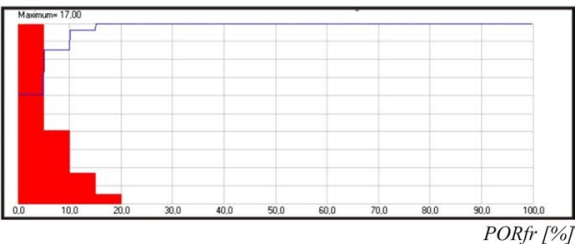

Fig. 8 Histograms of: a fracture aperture; $\mathbf{b}$ FPI values; $\mathbf{c}$ fracture porosity laboratory data

of the micro-range which would indicate the high sensitivity of the method and the possibilities of interpretation that have not yet been developed. This issue should be the subject of future research.

\section{Conclusions}

Summing up the performed research and obtained results, the following postulates regarding the optimization of the procedure for the interpretation of well $\operatorname{logs}$ data using laboratory measurements to identify and parameterize the fractured formation with double porosity can be formulated:

- Necessity to make each measurements exactly on the same rock material;

- Necessity to perform XRD, mercury and helium porosimetry, pycnometry, RockEval measurements for the separation of zones with an increased content of organic matter in order to correctly identify the origin of uranium anomalies; 
- Necessity to make such a number of measurements to obtain representative trends of variation of individual parameters for a given facies, lithology or stratigraphic stratification;

- In addition to standard measurements of well logging, it is necessary to perform an electrical imaging measurement using a borehole scanner-an obligatory measurement for obtaining information from the macro-range;

- Analyses of individual micro-, meso- and macro-ranges can be carried out separately, and then the impacts of general fracture systems can be balanced into whole volume of rock;

- Separate ranges of micro-, meso- and macro-fissures in practice are not perfectly separable, and it is necessary to conduct research in the future on the problem of determining the scope of common parts and the consequences that this brings for the results of the interpretation procedures which are used;

Acknowledgements Author expresses his thanks to Polish Oil and Gas Company, Warsaw, Poland, for granting permission for the use of geological and well logging information in the preparation of this article presented at the conference CAGG-AGH 10-13 September 2019 Krakow, Poland. Author would also like to express his thanks to Mr. Grzegorz Leśniak and Mrs. Barbara Darłak for the possibility of using the results of laboratory research on fracture porosity and fracture permeability used during the preparation of the publication manuscript.

\section{Compliance with ethical standards}

Conflict of interest Author states that the presented article will not cause a conflict of interest with any person or institution.

Open Access This article is distributed under the terms of the Creative Commons Attribution 4.0 International License (http://creativeco mmons.org/licenses/by/4.0/), which permits unrestricted use, distribution, and reproduction in any medium, provided you give appropriate credit to the original author(s) and the source, provide a link to the Creative Commons license, and indicate if changes were made.

\section{References}

Aguilera R (1976) Analysis of naturally fractured reservoirs from conventional well logs. JPT 6:764-771
Archie GE (1952) Classification of carbonate reservoir rocks and petrophysical considerations. AAPG Bull 6(2):278-298

Brie A, Johnson DL, Nurmi RD (1985) Effect of spherical pores on sonic and resistivity measurements. Paper W presented at the SPWLA 26th Annual Logging Symposium. Crain's Petrophysical Handbook https://www.spec2000.net/12-phifrac.htm

Dunham RJ (1962) Classification of carbonate rocks according to depositional texture. Mem Am Assoc Pet Geol 1:108-121

Dutta DJ, Madhavan S, Sundaram KM (1991) Characterization of dual porosity system in carbonates using sonic and resistivity measurements. Paper C presented at the SPWLA 40th Annual Logging Symposium

Kazatchenko E, Markov M, Mousatov A (2003) Determination of primary and secondary porosity in carbonate formations using acoustic data, paper SPE 84209

Kazatchenko E, Mousatov A (2002) Estimation of secondary porosity for carbonate formation using core data, total porosity and formation factor, paper SPE 77787

Leśniak G, Darłak B (1995) Laboratory investigation of petrophysical properties of fractured and vugged rocks. In: Modern exploration and improved oil and gas recovery methods, Cracow AGH 1995 conference proceedings, pp 203-204

Lucia FJ (1999) Carbonate reservoir characterization. Springer, New York, p 226

Luthi SM, Souhaite P (1990) Fracture apertures from electrical borehole scans. Geophysics 55:821-833

Narkiewicz M (2001) Lithostratygraphy, depositional, environments and diagnosis of the Devonian and carboniferous carbonates in the Rajbrot-Tarnawa area (Sub-Carpathian Arch), Scientific Works National Geologic Institute No CLXXIV, pp 9-33 (with English abstract)

Paduszyński J (1965) Estimation of micro-fractures density by random traverse method. Nafta 1:2-3 (in Polish)

Puskarczyk E, Krakowska P, Jędrychowski M, Habrat M, Madejski $\mathrm{P}$ (2018) A novel approach to the quantitative interpretation of petrophysical parameters using nano-CT: example of paleozoic carbonates. Acta Geophys 66(6):1453-1461. https://doi. org/10.1007/s11600-018-0219-x

Sowiżdżal K, Stadtmúller M (2010) Methodology of 3D fracture reservoir modeling. In: GEOPETROL 2010 conference proceedings, pp 105-111 (in Polish)

Stadtmúller M, Kowalik J (2012) Possibilities of fracture aperture evaluation based on well logs - methodical aspects. In: GEOPETROL 2012 conference proceedings, pp 355-358 (in Polish)

Urbaniec A (1998) Final report of the exploration well T-1 No. SW/K/801 Archives PGNiG S.A

Zhang J, Nie X, Xiao S et al (2018) Generating porosity spectrum of carbonate reservoirs using ultrasonic imaging log. Acta Geophys 66(2):191-201. https://doi.org/10.1007/s11600-018-0134-1 